\title{
Period and Birth-Cohort Effects on Age of First Phencyclidine (PCP) Use Among Drug Users in New York City, 1960 to 2000
}

\author{
WHITNEY K. BRYANT, MPH, DANIELLE C. OMPAD, PHD, JENNIFER AHERN, MPH, \\ YINGFENG WU, PHD, DAVID VLAHOV, PHD, AND SANDRO GALEA, MD, DRPH
}

\begin{abstract}
PURPOSE: The aim of the study is to determine period and birth-cohort effects in the early initiation of phencyclidine (PCP) use in drug users in New York City (NYC).

METHODS: We analyzed data collected from two surveys of street-recruited drug users in NYC. We used survival analysis and proportional hazards modeling to assess period and birth-cohort effects on risk for early initiation of PCP use.

RESULTS: Of 787 participants, 292 (37.1\%) had used PCP by the age of 23 years. Before 1987, there was a greater risk for initiation of PCP use through the age of 23 years (hazard ratio [HR] $=34.77$; $95 \%$ confidence interval [CI], 21.45-56.36). Proportional hazards modeling showed that those born in the 1971 to 1975 birth cohort compared with those born in 1976 to 1980 had a lower risk for initiation of PCP use through age 23 years $(\mathrm{HR}=0.58 ; 95 \% \mathrm{CI}, 0.37-0.91)$. Other significant predictors of PCP use by age 23 included white race and having been in a juvenile detention center.

CONCLUSIONS: There are period and birth-cohort differences in the likelihood of early initiation of PCP use. Changes in drug culture and social norms may influence the likelihood of initiation of PCP use. This may have implications for interventions aimed at slowing the nationwide increase in use of PCP. Ann Epidemiol 2006;16:266-272. (C) 2006 Elsevier Inc. All rights reserved.
\end{abstract}

KEY WORDs: Phencyclidine, PCP, Birth Cohorts, Period Effects, Initiation, Age.

\section{INTRODUCTION}

The National Institute on Drug Abuse defines "club drugs" as "drugs used by teens and young adults who are part of a nightclub, bar, rave, or trance scene" (1). These drugs typically include MDMA (ecstasy), phencyclidine (PCP), gamma hydroxybutyrate, rohypnol, amphetamines, lysergic acid diethylamide (LSD), and ketamine $(1,2)$. Reports suggested there may be a resurgence of club-drug use in the United States (3-5). Drug Enforcement Agency (DEA) reports trace the beginning of this increase to the mid to late 1990s (6). PCP has been one of the main drugs implicated in the return of club drug use (2). PCP has been used as a recreational drug since the late 1960s, although it

From the Center for Urban Epidemiologic Studies, New York Academy of Medicine, New York, NY (W.K.B., D.C.O., J.A., Y.W., D.V., S.G.); Department of Epidemiology, University of Michigan School of Public Health, Ann Arbor, MI (S.G.); Department of Epidemiology, Bloomberg School of Public Health, Johns Hopkins University, Baltimore, MD (D.V.); and Columbia University College of Physicians and Surgeons, New York, NY (W.K.B.).

Address correspondence to: Sandro Galea, M.D., Dr.P.H., Department of Epidemiology, University of Michigan School of Public Health, 1216 S. University, Ann Arbor, MI 48104. Tel.: (734) 647-9741; fax: (734) 998-0006. E-mail: sgalea@umich.edu.

This work was funded by grants no. DA-06534, DA-12801-S1, DA-017642-01, DA013146 and DA012801 from the National Institute on Drug Abuse.

Received March 8, 2005; accepted July 26, 2005. originally was developed for medical and surgical use as an anesthetic. It is classified as a dissociative anesthetic, but also has effects similar to such hallucinogens as LSD, such stimulants as amphetamines, and such central nervous system depressants as pentobarbital (7). Acute or subacute PCP intoxication can cause a number of psychiatric disorders, including toxic delirium, fulminant psychosis, and depression (8). PCP is a drug that can make users violent, delusional, paranoid, and catatonic and has gained notoriety by association with numerous homicides committed by those under its influence (9).

Previous studies suggested that PCP use increased during the 1970s (a phase often referred to as one of "epidemic" PCP use) and peaked in the 1980s (10-12). In the late 1980s, PCP went from being a drug used mainly by white adolescent males and females living in suburban areas to a drug used primarily by minority, particularly African-American, men in their 20s and 30s, centered in a handful of cities, particularly Washington, DC/Baltimore, Los Angeles, New York, St. Louis, New Orleans, and Chicago (13-16).

From January 1998 to December 2002, the Drug Abuse Warning Network of the US Department of Health and Human Services documented an increase of more than $240 \%$ in the number of emergency department visits related to PCP use, from 1,725 to 4,216 . DEA seizures of the drug increased by $24 \%$ from 2000 to 2001 (17). There was discussion in the 


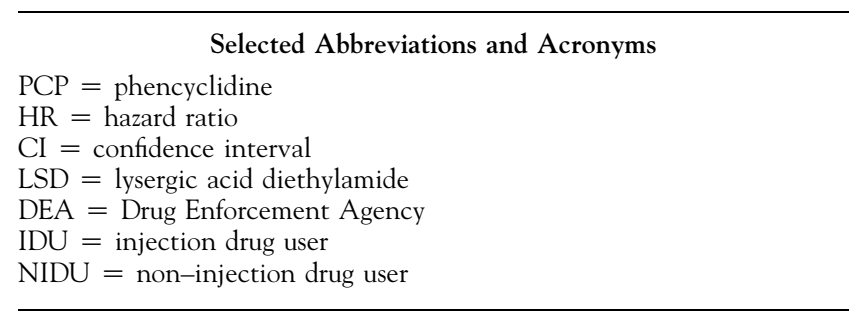

popular media of an increase in PCP trafficking and use in New York City (NYC), particularly in residents of NYC's surrounding suburbs (18). Emergency department visits related to PCP use in NYC increased by $67 \%$ from 2001 to 2002 (203 to 341 visits) (3). PCP also has been implicated as one of the more common club drugs used by habitual and nonhabitual drug users. A recent study of minority substance users in northern Manhattan found club-drug use to be common $(45.3 \%$ of Hispanics and $56.4 \%$ of African Americans) and PCP to be the most commonly used club drug, used at least once by $34.3 \%$ of respondents who had used club drugs (19).

The 2002 National Survey on Drug Use and Health, conducted by the Department of Health and Human Service's Substance Abuse and Mental Health Services Administration, reported trends in PCP use, including age of initiation. This study showed that the number of new PCP users by year sharply declined from 1975 to 1982 and remained low and fairly constant from 1983 to the early 1990s. From 1993 onward, the number of new users per year began to increase again, a trend that appears to have continued (10). The Substance Abuse and Mental Health Services Administration reported younger ages of initiation in the early 1970s (17 to 18 years old), later ages of initiation from the mid 1970s to mid 1990s (19 to 22 years old), followed by a decrease in age of initiation back to earlier levels from the mid 1990s through early 2000s (10). These studies suggested a changing prevalence of PCP use during the last 30 years. These trends could imply a return to the earlier, more widespread pattern of PCP use seen in the United States in the late 1970s, with the concomitant concerns for public health.

A string of murders in Brooklyn and Queens in winter 2003 ultimately were blamed on PCP use, bringing the drug to the attention of several NYC communities (9). Despite this increasing concern with PCP use, recent trends in use of the drug in NYC have been largely unexamined. Because of NYC's important place in the national portrait of drug abuse and the lack of information on changing trends in PCP use, we examined data from two surveys of habitual drug users in NYC to assess potential period and birth-cohort effects in age at first PCP use in habitual users during the past 40 years to identify changing trends in PCP use.

\section{METHODS}

\section{Subject Recruitment}

We used data from two surveys of street-recruited habitual drug users in NYC. Potential participants were recruited for two ongoing studies $(19,20)$ of injection drug users (IDUs) and non-IDUs (NIDUs) by using street outreach techniques described elsewhere $(21,22)$.

Briefly, outreach workers engaged drug users in conversations about ongoing studies at the research storefront and places in the community where drugs were bought and/or used. Both IDUs and NIDUs were recruited between August 2000 and August 2003 from three NYC boroughs in neighborhoods with an active observable drug economy. Interviews were conducted in two storefronts in East Harlem and the South Bronx and from a recreational vehicle parked in Bedford-Stuyvesant in Brooklyn, Jamaica, Queensbridge in Queens, and the Lower East Side of Manhattan. Potential participants completed a screening demographic interview. The IDU study was designed to study correlates and predictors of hepatitis $\mathrm{C}$ virus infection and therefore targeted young, recently initiated IDUs at risk for hepatitis $C$ virus infection. Participants were eligible for the IDU study if they were 15 to 40 years of age and reported injecting heroin or cocaine at least once in the last 2 months, but for no longer than 5 years. The NIDU study was designed to study correlates and predictors of transition to injection drug use. Participants were eligible for the NIDU study if they were 15 to 40 years of age and reported non-injecting drug use of heroin or cocaine at least once per week in the last 2 months, but for no longer than 10 years, and no history of injecting drug use. Only participants who currently were residents of NYC were included in this analysis.

Participants were reimbursed $\$ 20$ for their participation. The institutional review board of the New York Academy of Medicine approved the study. Informed consent was obtained in writing from all study participants. Baseline data collected through March 2004 from both the IDU and NIDU studies were combined for this analysis.

\section{Data Collection}

After obtaining informed consent, eligible participants completed a standardized detailed risk-behavior questionnaire administered by trained interviewers in English or Spanish. We asked about sociodemographic characteristics, type and frequency of drug use, sexual behaviors, and sexual partnerships. The presence or absence of prior injection drug use was confirmed during the interviewing process and by phlebotomist assessment of injection stigmata (track marks). Sociodemographic characteristics included age, race, sex, education, recent homelessness, main income source, and sexual identity. We examined recent frequency 
of substance use in the last 2 months, focusing on the most commonly used substances, including marijuana, heroin, LSD, crack, and cocaine. Age at first use of PCP and other substances was collected through self-report.

\section{Statistical Methods}

To ensure that all study participants had an equivalent risk period for starting PCP use, we included only respondents 23 years and older in the analysis and considered risk for first PCP use by age 23 . The age of 23 years was used because it was the average age of initiating PCP use plus one SD (mean age of initiating $\mathrm{PCP}=19$ years; $\mathrm{SD}=4$ years). By restricting the analysis to participants who were 23 years or older at the interview, all participants had the full 23-year at-risk period at the interview, and participants of all ages at the interview had equal time in which to try PCP. All survival analysis methods make an assumption that censoring is unrelated to the risk for the outcome within exposure strata; given that periods and birth cohorts were key variables of interest in this analysis, these restrictions were necessary to meet this assumption (23).

Initially, IDUs and NIDUs were examined separately to assess differences in associations of interest in this analysis. There were no substantive differences in period and birthcohort predictors of PCP use onset between IDUs and NIDUs, and as such, the groups were combined for all analyses presented here.

We examined bivariate associations of sociodemographic factors and drug-use behaviors with PCP use by age 23 by using chi-square tests. Use of specific drugs (marijuana, cocaine, heroin, crack, and LSD) was restricted to use before the initiation of PCP use for initiators and to use before the age of 19 years for others. The age of 19 years was selected to assess prior drug use for those who did not use PCP because it is the mean age of initiating PCP use in those who initiate use, and on average, this definition will assess other drug use up to the same age for both groups, i.e., PCP use initiators and noninitiators.

We used Kaplan-Meier survival analyses to assess period and birth-cohort effects separately. Age at first PCP use was the incident time in analyses. The period survival plot was stratified by date of first use of PCP: before or after 1987, when national reports suggest that PCP use was at its lowest (10). The birth-cohort survival plot was stratified by participant date of birth, making four separate groupings: those born between 1961 and 1965, 1966 and 1970, 1971 and 1975, and 1976 and 1980. Differences between curves were determined by using log-rank tests.

We used proportional hazards models to determine the significance of period and birth-cohort effects when controlling for other relevant covariates. Both the period and birthcohort models were adjusted for age, sex, race/ethnicity, education, any time in a juvenile detention center, and dropping out of school. Although considering other drugs that are associated with PCP initiation is useful in describing the constellation of drugs that tend to be used by the same individuals, there is no plausible mechanism that would suggest these drugs themselves cause PCP use initiation, and as such, use of other drugs was not considered a potential confounder in multivariable models. In addition, reinforcing this approach, inclusion of prior drug use variables in proportional hazards models did not appreciably change the relations reported in this analysis.

TABLE 1. Correlates of early initiation of PCP use in habitual drug users in New York City

\begin{tabular}{|c|c|c|c|c|c|}
\hline & \multicolumn{2}{|c|}{ Total sample } & \multicolumn{2}{|c|}{ Used $\mathrm{PCP} \leqslant 23$ years old } & \multirow[b]{2}{*}{$p$} \\
\hline & $N$ & $\%$ & $N$ & $\%$ & \\
\hline Total & 787 & 100.00 & 292 & 37.10 & \\
\hline \multicolumn{6}{|l|}{ Age (years) } \\
\hline$<27$ & 236 & 29.99 & 94 & 39.83 & \multirow[t]{2}{*}{0.30} \\
\hline$\geqslant 27$ & 551 & 70.01 & 198 & 35.93 & \\
\hline \multicolumn{6}{|l|}{ Sex } \\
\hline Male & 569 & 73.04 & 216 & 37.96 & \multirow[t]{2}{*}{0.49} \\
\hline Female & 210 & 26.96 & 74 & 35.24 & \\
\hline \multicolumn{6}{|l|}{ Race } \\
\hline White & 31 & 3.94 & 18 & 58.06 & \multirow[t]{4}{*}{0.02} \\
\hline African American & 277 & 35.20 & 97 & 35.02 & \\
\hline Hispanic & 430 & 54.64 & 153 & 35.58 & \\
\hline Others & 49 & 6.23 & 24 & 48.98 & \\
\hline \multicolumn{6}{|l|}{ Education } \\
\hline$<$ High school & 417 & 53.19 & 161 & 38.61 & \multirow[t]{2}{*}{0.36} \\
\hline$\geqslant$ High school & 367 & 46.81 & 130 & 35.42 & \\
\hline \multicolumn{6}{|l|}{$\begin{array}{l}\text { Ever in juvenile } \\
\text { center }\end{array}$} \\
\hline No & 602 & 77.78 & 206 & 34.22 & \multirow[t]{2}{*}{$<0.01$} \\
\hline Yes & 172 & 22.22 & 83 & 48.26 & \\
\hline \multicolumn{6}{|l|}{$\begin{array}{l}\text { Dropped out of } \\
\text { school }\end{array}$} \\
\hline No & 229 & 29.10 & 73 & 31.88 & \multirow[t]{2}{*}{0.05} \\
\hline Yes & 558 & 70.90 & 219 & 39.25 & \\
\hline \multicolumn{6}{|l|}{ Used marijuana $^{\mathrm{a}}$} \\
\hline No & 77 & 9.78 & 14 & 18.18 & \multirow[t]{2}{*}{$<0.01$} \\
\hline Yes & 710 & 90.22 & 278 & 39.15 & \\
\hline \multicolumn{6}{|l|}{ Used cocaine $^{\mathrm{a}}$} \\
\hline No & 269 & 34.18 & 107 & 39.78 & \multirow[t]{2}{*}{0.26} \\
\hline Yes & 518 & 65.82 & 185 & 35.71 & \\
\hline \multicolumn{6}{|l|}{ Used heroin $^{\mathrm{a}}$} \\
\hline No & 531 & 67.47 & 198 & 37.29 & \multirow[t]{2}{*}{0.88} \\
\hline Yes & 256 & 32.53 & 94 & 36.72 & \\
\hline \multicolumn{6}{|l|}{ Used crack $^{\mathrm{a}}$} \\
\hline No & 566 & 71.92 & 204 & 36.04 & \multirow[t]{2}{*}{0.32} \\
\hline Yes & 221 & 28.08 & 88 & 39.82 & \\
\hline \multicolumn{6}{|l|}{$\begin{array}{l}\text { Used lysergic acid } \\
\text { diethylamide }^{\text {a }}\end{array}$} \\
\hline No & 622 & 79.03 & 190 & 30.55 & \multirow[t]{2}{*}{$<0.01$} \\
\hline Yes & 165 & 20.97 & 102 & 61.82 & \\
\hline
\end{tabular}

$\mathrm{PCP}=$ phencyclidine

a Used before PCP use onset or age 19 for those who did not use PCP before age 23 . 


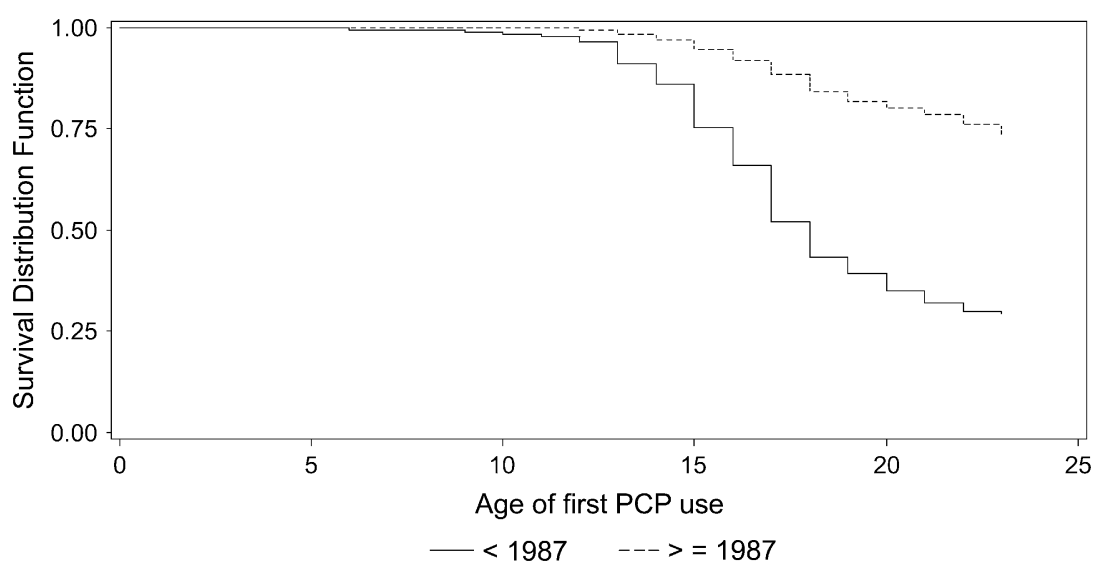

FIGURE 1. Kaplan-Meier survival curve of phencyclidine (PCP) use initiation before age 23 by period cohort. Log-rank test, chi-square $p<0.01$.

\section{RESULTS}

Of a total of 787 individuals from the two studies, 292 (37.1\%) had used PCP by the time they were 23 years old. In this sample of drug users, $70 \%$ of participants were 27 years or older, $73 \%$ were male, $3.9 \%$ were white, $35.2 \%$ were African American, and 54.6\% were Hispanic (Table 1). Of these respondents, $53.2 \%$ did not complete high school, $70.9 \%$ dropped out of school, and $22.2 \%$ spent time in a juvenile detention center. In terms of drug use, $90.2 \%$ of respondents had used marijuana, $65.8 \%$ had used cocaine, $32.5 \%$ had used heroin, $28.1 \%$ had used crack, and $21.0 \%$ had used LSD.

Bivariate correlates of PCP use by age 23 were race (58.1\% of whites, $35.0 \%$ of African Americans, $35.6 \%$ of Hispanics, and $49.0 \%$ of those of other races; $p=0.02$ ) and having been in a juvenile center $(48.3 \%$ of those who had versus $34.2 \%$ of those who had not; $p<0.01$ ). Of prior

TABLE 2. Proportional hazards model predicting time to PCP use initiation in 763 PCP users by period cohort

\begin{tabular}{|c|c|c|c|c|c|}
\hline & $\begin{array}{l}\text { Parameter } \\
\text { estimate }\end{array}$ & SE & $p$ & $\begin{array}{l}\text { Hazard } \\
\text { ratio }\end{array}$ & $\begin{array}{c}95 \% \\
\text { Confidence } \\
\text { interval }\end{array}$ \\
\hline Period $<1987^{\mathrm{a}}$ & 3.55 & 0.25 & $<0.01$ & 34.77 & $21.45-56.36$ \\
\hline Age & -0.20 & 0.02 & $<0.01$ & 0.82 & $0.79-0.85$ \\
\hline Female & -0.16 & 0.14 & 0.28 & 0.86 & $0.64-1.14$ \\
\hline African American ${ }^{\mathrm{b}}$ & -0.78 & 0.27 & $<0.01$ & 0.46 & $0.27-0.78$ \\
\hline Hispanic $^{b}$ & -0.71 & 0.26 & 0.01 & 0.49 & $0.30-0.82$ \\
\hline Others ${ }^{\mathrm{b}}$ & -0.09 & 0.32 & 0.77 & 0.91 & $0.49-1.70$ \\
\hline$\geqslant$ High school & -0.04 & 0.15 & 0.80 & 0.96 & $0.72-1.30$ \\
\hline Ever in juvenile center & 0.53 & 0.14 & $<0.01$ & 1.69 & $1.29-2.22$ \\
\hline Dropped out of school & 0.29 & 0.17 & 0.10 & 1.34 & $0.95-1.88$ \\
\hline
\end{tabular}

$\mathrm{PCP}=$ phencyclidine.

${ }^{\text {aPeriod }} \geqslant 1987$ is reference group.

${ }^{b}$ White is reference group. drug use variables, marijuana $(39.2 \%$ versus $18.2 \%$; $p<$ $0.01)$ and $\operatorname{LSD}(61.8 \%$ versus $30.6 \%$; $p<0.01)$ were associated positively with PCP use.

Kaplan-Meier survival curves by period, stratified before and after 1987, are shown in Fig. 1. This figure shows that risk for PCP initiation by age 23 was greater before 1987 than after 1987 (log-rank test, $p<0.01)$.

A proportional hazards model comparing the likelihood of having tried PCP at any age up to 23 years for the period up to 1987 and the period after 1987 shows that two variables were significantly associated with increased risk for using PCP by age 23: earlier period (hazard ratio [HR] = 34.77 ; 95\% confidence interval [CI], 21.45-56.36) and having ever been in a juvenile center $(\mathrm{HR}=1.69 ; 95 \% \mathrm{CI}$, 1.29-2.22; Table 2). Other variables associated with a significantly decreased risk for PCP use were age at time of interview $(\mathrm{HR}=0.82 ; 95 \% \mathrm{CI}, 0.79-0.85)$, African-American race $(\mathrm{HR}=0.46 ; 95 \% \mathrm{CI}, 0.27-0.78)$, and Hispanic race $(\mathrm{HR}=0.49 ; 95 \% \mathrm{CI}, 0.30-0.82)$.

Kaplan-Meier survival curves by birth cohort, stratified by birth-year groups 1961 to 1965,1966 to 1970,1971 to 1975, and 1976 to 1980, are shown in Fig. 2. Test for equality of survival curves by birth cohort showed a significant difference (log-rank test, $p=0.03$ ). A second test comparing the 1971 to 1975 birth cohort with the others showed the difference to be significant (log-rank test, $p<0.01$ ). This figure shows that those born in the 1971 to 1975 birth cohort generally had lower risk for initiation of PCP use by age 23.

In a proportional hazards model predicting risk for PCP use by age 23, compared with those born in 1976 to 1980 , those born in 1971 to 1975 had decreased risk for using PCP through age $23(\mathrm{HR}=0.58 ; 95 \% \mathrm{CI}, 0.37-0.91$; Table 3). Compared with white respondents, AfricanAmerican and Hispanic respondents had lower risks for using $\mathrm{PCP}(\mathrm{HR}=0.38 ; 95 \% \mathrm{CI}, 0.22-0.65$ and $\mathrm{HR}=0.41$; 


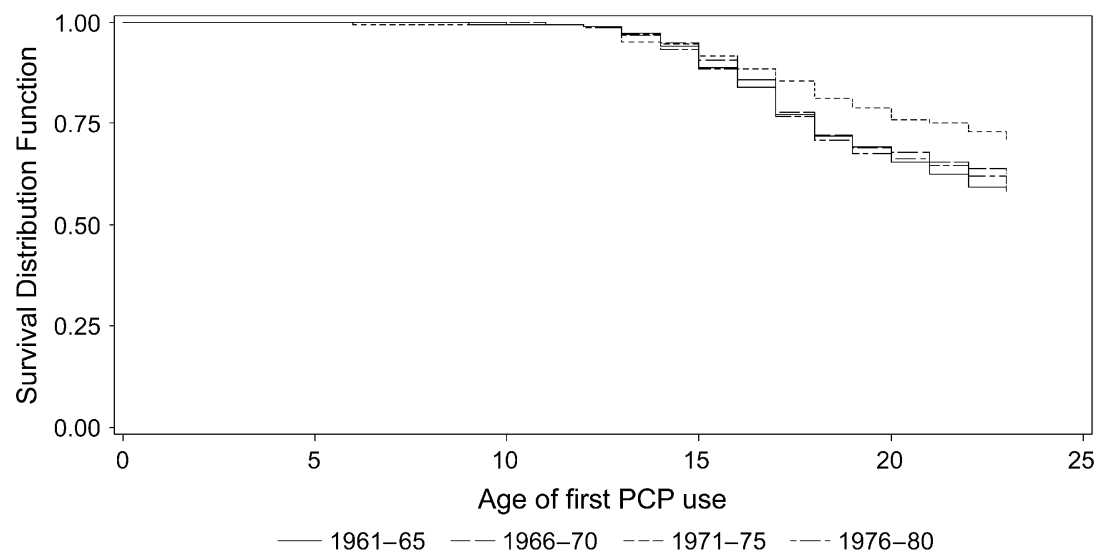

FIGURE 2. Kaplan-Meier survival curve of phencyclidine (PCP) use initiation before age 23 by birth cohort. Log-rank test, chi-square $p<0.01$.

95\% CI, 0.24-0.68, respectively). Time in a juvenile detention center also was associated with increased risk for PCP use by age $23(\mathrm{HR}=1.68 ; 95 \% \mathrm{CI}, 1.28-2.20)$.

\section{DISCUSSION}

We documented period effects and birth-cohort effects on risk for early initiation of PCP use in a group of predominantly minority street-recruited drug users in NYC. Risk for PCP initiation by age 23 was greater before 1987 than after 1987. In addition, participants born during 1971 to 1975 had the lowest risk for initiating use of PCP at a given age. Positive predictors for PCP use by age 23 were white race (compared with African-American and Hispanic race) and having been in a juvenile detention center.

Our results are consistent with other observations that there has been a change over time in PCP use initiation in young people $(10,11,13,15)$. Before 1987, a greater percentage of drug users in our cohort had used PCP by age 23 than after 1987 . We also found that different birth cohorts had differing likelihoods of early initiation of use. Although the primary focus of public health interventions during the past three decades has been on prevention of adolescent and young adult initiation of PCP (15), we found that risk for early initiation of PCP use was decreasing throughout the 1970s and 1980s (15, 24). Although we are not aware of other recent work that explicitly assessed period and birth-cohort effects on PCP use patterns, other reports provided evidence that corroborates our findings. In 1978, national reports found that average age of first use of PCP was approximately 13 years (25). From 1976 to 1987, the number of high school seniors reporting PCP use in the prior 30 days and the number of 12- to 17-yearolds reporting ever having used PCP steadily declined (26). From 1979 to 1982 , the number of 18 - to 25-year- olds reporting having used PCP declined from $14.5 \%$ to $10.5 \%$, and concurrently, the age of emergency department patients making visits because of PCP use increased (26). Subsequently, from 1979 to 1987, the percentage of American high school seniors reporting ever having tried PCP decreased from $12.8 \%$ to $3 \%$ (27). This decline in use in young people seems to have continued through the late 1980s and early 1990s and is consistent with our observation of a birth-cohort effect in risk for early PCP use initiation.

It was suggested that PCP use follows cyclical trends, declining when a new generation of users experiences the drug's side effects. Other factors implicated in periodic declines in rates of use are intense public health campaigns warning of the drug's effects, targeted primarily at children and adolescents; restrictions on the purchase of pyridine (a necessary ingredient for the manufacture of PCP); and government crackdowns on production and possession of

TABLE 3. Proportional hazards model predicting time to PCP use initiation in 763 PCP users by birth cohort

\begin{tabular}{|c|c|c|c|c|c|}
\hline & $\begin{array}{l}\text { Parameter } \\
\text { estimate }\end{array}$ & SE & $p$ & $\begin{array}{l}\text { Hazard } \\
\text { ratio }\end{array}$ & $\begin{array}{c}95 \% \\
\text { Confidence } \\
\text { interval }\end{array}$ \\
\hline Born $1961-1965^{a}$ & -0.31 & 0.56 & 0.58 & 0.74 & $0.25-2.20$ \\
\hline Born $1966-1970^{a}$ & -0.38 & 0.38 & 0.33 & 0.69 & $0.32-1.45$ \\
\hline Born $1971-1975^{a}$ & -0.55 & 0.23 & 0.02 & 0.58 & $0.37-0.90$ \\
\hline Age & 0.04 & 0.04 & 0.33 & 1.04 & $0.96-1.12$ \\
\hline Female & -0.14 & 0.15 & 0.35 & 0.87 & $0.66-1.16$ \\
\hline Black $^{\mathrm{b}}$ & -0.97 & 0.27 & $<0.01$ & 0.38 & $0.22-0.65$ \\
\hline Hispanic $^{\mathrm{b}}$ & -0.90 & 0.27 & $<0.01$ & 0.41 & $0.24-0.68$ \\
\hline Others ${ }^{\mathrm{b}}$ & -0.36 & 0.32 & 0.26 & 0.70 & $0.37-1.31$ \\
\hline$\geqslant$ High school & -0.07 & 0.15 & 0.64 & 0.93 & $0.70-1.25$ \\
\hline Ever in juvenile center & 0.52 & 0.14 & $<0.01$ & 1.68 & $1.28-2.20$ \\
\hline Dropped out of school & 0.27 & 0.17 & 0.12 & 1.31 & $0.93-1.84$ \\
\hline
\end{tabular}

${ }^{\text {a Born }} 1976$ to 1980 is reference group.

bWhite is reference group. 
the drug, as well as movement of the drug from a DEA schedule III classification to a place on the more tightly regulated schedule II (the same schedule as cocaine) $(26,28)$. In metropolitan areas, in which PCP use appears to have remained concentrated, amount of PCP use appears to be related to factors governing the consumption of "more highly coveted" drugs, such as crack cocaine (15). Price and ease of acquisition of those more desirable drugs may drive PCP use trends (15).

The degree to which our results are generalizable outside NYC is unknown, and these changes in PCP use may be confined to this geographic area of study. We note that other work in the Washington, DC/Baltimore area generally found rates of PCP use to be greater than in New York and showed an increase in PCP use since the late 1990s (3). We do not know if our observations of period and birth cohorts are generalizable to other different demographic groups than those studied here. Also, period and birthcohort effects may differ between subsets of drug users. For example, persons who predominantly buy and use PCP on the street may be different than those who predominantly buy and use PCP in clubs. However, we note that our findings highlight the more general phenomenon of a particular drug's rise and fall over time. This may be important to consider in the context of drug use surveillance and prediction.

Although PCP and methamphetamines are often considered club drugs, they also often are sold in the streets $(5,19)$. We do not have information on this to assess whether PCP use was within a club or in another context. Recent reports suggested that club drugs are being purchased increasingly on the street, something that would need to be considered in basing interventions on these findings $(29,30)$. This study focuses on habitual drug users. It is possible that more casual recreational users make up the bulk of the increase in PCP use seen in the past decade, and that these users follow different age and demographic patterns than those documented here. Our sample is predominantly male. It was suggested that female PCP users are different in their reasons for initiating and continuing to use PCP (6), and as such, our results must be generalized with caution to populations with different demographic composition.

Notwithstanding these limitations, our data suggest a changing likelihood of PCP use by a given age during different periods and among different birth cohorts of habitual drug users in NYC during the past 30 years. Those who initiated PCP use after 1987, when PCP popularity was at its nadir, were less likely to have initiated PCP use by age 23 than those who initiated use before 1987. Understanding secular trends in club-drug use patterns is essential for designing effective risk-reduction interventions and to identify likely patterns in cohorts at risk for using these drugs in the future. Period and birth-cohort effects may be present in the use of other drugs over time; understanding such patterns may be important for efforts aimed at surveillance, prediction, and minimizing use of illicit drugs.

The authors thank the participants of the Center for Urban Epidemiologic Studies' Harlem Outreach Prevention and Education, and Hepatitis C Studies.

\section{REFERENCES}

1. National Institute on Drug Abuse. NIDA Info Facts: Club Drugs, 2004. Available at: http://www.nida.nih.gov/Infofax/clubdrugs.html. Accessed September 7, 2004.

2. Substance Abuse and Mental Health Services Administration (SAMHSA). National Survey of Drug Use and Health, 2003. Office of Applied Studies, Department of Health and Human Services. Available at: http://www.oas.samhsa.gov/NHSDA/2k2NSDUH/HTML/Sect4peTabs 1 to76.htm\#tab4.26a and http://www.oas.samhsa.gov/ecstasy.htm\#Trends. Accessed July 9, 2004.

3. Drug Abuse Warning Network (DAWN). Emergency Department Trends from DAWN: 1995-2002. Department of Health and Human Services Substance Abuse and Mental Health Services Administration. Available at: http://dawninfo.samhsa.gov/pubs_94_02/edpubs/2002final/. Accessed June 27, 2004.

4. National Institute on Drug Abuse. Club Drugs Take Center Stage in New National Education and Prevention Initiative by NIDA and National Partners, 1999. Available at: http://165.112.78.61/MedAdv/99/NR-122. html. Accessed July 8, 2004.

5. National Institute on Drug Abuse. NIDA Community Drug Alert Bulletin -Club Drugs, 2002. Available at: http://165.112.78.61/ClubAlert/Club drugsAlert.html. Accessed July 8, 2004.

6. Fishbein DH. Female PCP-using detainees: Proneness to violence and gender differences. Addict Behav. 1996;21:155-172.

7. Carrol ME. PCP and hallucinogens. Adv Alcohol Subst Abuse. 1990;9:167-190.

8. Gorelick DA, Wilkins JN. Inpatient treatment of PCP abusers and users. Am J Drug Alcohol Abuse. 1989;15:1-12.

9. Dewan SK. A drug feared in the '70's is tied to suspect in killings. The New York Times. April 6, 2003;A5:31.

10. Substance Abuse and Mental Health Services Administration (SAMHSA). Ecstasy, Other Club Drugs, \& Other Hallucinogens. Department of Health and Human Services, 2002. Available at: http://oas. samhsa.gov/Ecstasy.htm. Accessed September 7, 2004.

11. Newmeyer JA. The epidemiology of PCP use in the late 1970s. J Psychedelic Drugs. 1980;12:211-215.

12. Davis BL. The PCP epidemic: A critical review. Int J Addict. 1982;17: 1137-1155.

13. Lerner SE, Burns RS. Phencyclidine use among youth: History, epidemiology, and acute and chronic intoxication. In: Petersen R, ed. National Institute of Drug Abuse Research Monograph 21. Washington, DC: US Government Printing Office; 1978:66-118.

14. Graeven D. Patterns of phencyclidine use. Phencyclidine (PCP) abuse: An appraisal. In: Petersen R, ed. National Institute of Drug Abuse Research Monograph 21. Washington, DC: US Government Printing Office; 1978:176-182.

15. Thombs DL. A review of PCP trends and perceptions. Public Health Rep. 1989;104:325-328.

16. Chan K, Matthews WS, Saxena S, Wong ET. Frequency of cocaine and phencyclidine detection at a large urban public teaching hospital. J Anal Toxicol. 1993;17:299-303. 
17. Smalley S, Rosenberg D. "'I felt like I wanted to hurt people'.” Newsweek. July 22, 2002:32-33.

18. Wren C. "60's Drug is back, police say, as they announce arrests." New York Times. April 12, 1996;B4:3.

19. Ompad DC, Galea S, Fuller CM, Phelan D, Vlahov D. Club drug use among minority substance users in New York City. J Psychoactive Drugs. 2004;36:397-399.

20. Koblin BA, Factor SH, Wu Y, Vlahov D. Hepatitis C virus infection among non-injecting drug users in New York City. J Med Virol. 2003;70:387-390.

21. Diaz T, Des Jarlais DC, Vlahov D, Perlis TE, Edwards V, Friedman SR, et al. Factors associated with prevalence of hepatitis C: Differences among young adult injection drug users in lower and upper Manhattan, New York City. Am J Public Health. 2001;91:23-30.

22. Diaz T, Vlahov D, Greenberg B, Cuevas Y, Garfein R. Sexual orientation and HIV infection prevalence among young Latino injection drug users in Harlem. J Women's Health Gend Based Med. 2001;10:371-380.

23. Rothman KJ, Greenland S. Modern Epidemiology. Philadelphia: Lippincott, Williams \& Wilkins; 1998.

24. DeAngelis GG, Goldstein E. Long term treatment of adolescent PCP abusers. Phencyclidine (PCP) abuse: An appraisal. In: Petersen RC, Stillman RC, eds. National Institute of Drug Abuse Research Monograph 21,
DHEW Pub. No. 78-728. Washington, DC: US Government Printing Office; 1978:254-271.

25. Fauman MA, Fauman BJ. The psychiatric aspects of chronic phencyclidine use: A study of chronic PCP users. In: Petersen R, ed. National Institute of Drug Abuse Research Monograph 21. Washington, DC: US Government Printing Office; 1978.

26. Crider R. Phencyclidine: Changing abuse patterns. Phencyclidine: An update. In: Clouet DH, ed. National Institute of Drug Abuse Research Monograph 64. Washington, DC: US Government Printing Office; 1986:163-173.

27. Johnston LD, O'Malley PM, Bachman JG. Illicit Drug Use, Smoking, and Drinking by America's High School Students, College Students, and Young Adults, 1975-1987. Department of Health and Human Services Publications No. (ADM 89-1602). Rockville, MD: National Institute on Drug Abuse; 1988

28. Garey RE, Daul GC, Samuels MS, Ragan FA, Hite SA. PCP abuse in New Orleans: A six-year study. Am J Drug Alcohol Abuse. 1987;13:135-144.

29. Mokhlesi B, Garimella PS, Joffe A, Velho V. Street drug abuse leading to critical illness. Intensive Care Med. 2004;30:1526-1536.

30. Community Epidemiology Work Group. Epidemiologic Trends in Drug Abuse, vol 1: Proceedings From the Community Epidemiology Work Group. Washington, DC: National Institute on Drug Abuse; 2001. 